\title{
Clinical Evaluation of the Captopril Screening Test for Primary Aldosteronism
}

\author{
Shojiro Naomi, M.D., Taisuke IwaokA, M.D., \\ Teruhisa Umeda, M.D., Junnosuke Inove, M.D., \\ Shinichiro Hamasaki, M.D., Fumihiro Mrura, M.D., \\ Yumiko Fujn, M.D., and Tatsuo SATo, M.D.
}

\section{SUMMARY}

In order to investigate the validity of angiotensin converting enzyme inhibition with captopril as a screening test for primary aldosteronism (PA), $50 \mathrm{mg}$ of captopril were administered orally to 7 patients with $\mathrm{PA}, 17$ with essential hypertension $(\mathrm{EH}), 5$ with renovascular hypertension (RVH), 2 with renoparenchymal hypertension (RH) and 8 normal volunteers.

The plasma aldosterone concentration (PAC) was suppressed to less than $15 \mathrm{ng} / \mathrm{dl}$ in all of the $\mathrm{EH}, \mathrm{RVH}$ and $\mathrm{RH}$ patients and normal subjects $90 \mathrm{~min}$ after administration of captopril, but not suppressed in 6 of 7 patients with PA. In addition, the plasma renin activity (PRA) was increased to greater than $1 \mathrm{ng} / \mathrm{ml} / \mathrm{h}$ in 10 of 17 patients with $\mathrm{EH}$ and in all with $\mathrm{RVH}, \mathrm{RH}$ and the normal controls, but to less than that in 6 of $7 \mathrm{PA}$ and the remaining EH patients. The PAC to PRA ratio after captopril was greater than 20 in all patients with PA, while it remained below 20 in $\mathbf{E H}$, RVH and RH patients and normal controls.

From these results, we conclude that the PAC to PRA ratio in the captopril administration test is a simple and useful tool to detect $\mathrm{PA}$ in hypertensive patients. In addition, the test has a great advantage in that it can be safely applied to outpatients with relatively severe hypertension.

\section{Additional Indexing Words:}

Primary aldosteronism Aldosterone to renin ratio Captopril

From the Department of Internal Medicine III, Kumamoto University Medical School, Ku* mamoto, Japan.

Supported by a Grant from the Ministry of Health and Welfare "Disorders of adrenal hormone" Research Committee, Japan, 1984.

Address for reprint: Shojiro Naomi, M.D., Department of Internal Medicine III, Kumamoto University Medical School, 1-1-1 Honjo, Kumamoto 860, Japan.

Received for publication August 27, 1984.

Manuscript revised December 28, 1984. 
DRIMARY aldosteronism (PA), described initially by Conn, "' is a syndrome 1 caused by excessive production of aldosterone from an adrenal tumor. Hypertension, hypokalemic alkalosis, normal output of urinary 17-hydroxycortico-steroids and excessive production of aldosterone were original features of the syndrome. Latcr, the marked suppression of plasma renin activity (PRA), resulting from plasma volume expansion caused by mineralocorticoid cxcess, provided a potential tool to detect the surgically curable hypertension of PA. ${ }^{2}$ However, extensive studies of PRA in hypertensive patients revealed that a considerable population of essential hypertensive (EH) patients showed suppressed PRA in the absence of excess levels of aldosterone. Furthermore, several cases of PA associated with high PRA have been reported, ${ }^{3,4)}$ mostly resulting from renal damage due to longstanding severe hypertension. Thus, the estimation of basal and or stimulated PRA is not adequate to establish the diagnosis of PA. Rather, it is necessary to demonstrate that the production of aldosterone is autonomous to establish the diagnosis of PA. For this purpose, maneuvers to suppress the renin-angiotensin-aldosterone system, such as high salt intake, ${ }^{5)}$ exogenous mineralocorticoid administration ${ }^{61}$ and acute saline infusion ${ }^{71}$ have been developed. Among these, the saline infusion test has been nominated as the most simple and reliable method. However, it is sometimes difficult to perform in the severely hypertensive patient. Lyon et $a^{8)}$ have reported that the oral administration of captopril, a potent inhibitor of angiotensin I converting enzyme, might be an alternative method. Both captopril and saline infusion can lower circulating angiotensin II levels and decrease production of aldosterone in $\mathrm{EH}$, renovascular ( $\mathrm{RVH}$ ) and renoparenchymal hypertension $(\mathrm{RH})$. However, these have no effect on aldosterone production in patients with PA because of its independency from the renin angiotensin system. $^{9)}$ We have previously reported ${ }^{10)}$ on the clinical usefulness of the captopril administration test in the diagnosis of PA. Those results were not conclusive because of an insufficient number of patients. The present study was undertaken to confirm the validity of this test to differentiate PA from other forms of hypertension.

\section{Patients and Methods}

Seven patients with PA, 17 with $\mathrm{EH}, 5$ with RVH, 2 with $\mathrm{RH}$ and 8 normal subjects were studicd. All patients were admitted to our hospital and underwent detailed physical examination, routine blood tests, urinalysis and several hormonal profilings including PRA, plasma aldosterone concentration (PAC), urinary output of catecholamines, $17 \mathrm{KS}$ and 17 OHCS. 
All medications were discontinued after admission.

The diagnosis of PA was made by the presence of elevated PAC and subnormal PRA after a $1 \mathrm{mg} / \mathrm{Kg}$ intravenous injection of furosemide and 2 hours of ambulation. Subsequent adrenal venous sampling, scintiscans with ${ }^{75}$ Se-sintadren with dexamethasone suppression, and high resolution computed tomography were performed. An unilateral adrenal adenoma was proven in all patients with PA. Therefore, no case of idiopathic hyperaldosteronism was included in the present study.

The diagnosis of $\mathrm{RVH}$ was made by rapid sequence intravenous pyelography, renal arteriography and PRA determination of renal venous samples. The diagnosis of RH was established by histological study of biopsied renal specimens. In 17 patients with EH, PA was excluded by normal basal $\mathrm{PAC}$ and suppressed PAC below $10 \mathrm{ng} / \mathrm{dl}$ after 7 days of sodium loading of $340 \mathrm{mEq} /$ day. The 8 normal volunteers were healthy and had no history of hypcrtension, renal disease or endocrine disorders. Informed consent was obtained from all of patients and normal volunteers before being studied.

The hypertensive patients were studied after 7 hospital days on a daily sodium intake of $170 \mathrm{mEq}$, whereas normal subjects were studied without salt restriction. After an overnight fast and $30 \mathrm{~min}$ bed rest, the first blood sample was collected for basal PAC and PRA followed by oral administration of $50 \mathrm{mg}$ captopril. The second sample blood was taken $90 \mathrm{~min}$ after the drug was given. PAC and PRA were determined by RIA as previously reported. ${ }^{10)}$ The data were statistically analyzed by Student's t-test. Grouped data were expressed as the mean $\pm \mathrm{SD}$.

\section{Results}

Only one of 17 patients with $\mathrm{EH}$ showed a serum potassium level of less than $3.5 \mathrm{mEq} / \mathrm{L}$. Six of 7 patients with PA had serum potassium levels of less than $3.5 \mathrm{mEq} / \mathrm{L}$, but the one remaining patient had persistently normal serum potassium levels except for those during sodium loading. Serum potassium levels in all of RVH and RH patients were within normal limits (Table I).

PRA levels after stimulation with i.v. furosemide and upright posture in all patients are shown in Fig. 1. In all patients with PA and 2 patients with $\mathrm{EH}, \mathrm{PRA}$ failed to be stimulated by the manipulation.

Individual captopril test data for each patient are given in Table II. In all EH, 3 of $5 \mathrm{RVH}$ and 7 of 8 normal subjects, PAC before drug were less than $15 \mathrm{ng} / \mathrm{dl}$ and greater than $15 \mathrm{ng} / \mathrm{dl}$ in all of the PA and RH patients, while PAC levels at $90 \mathrm{~min}$ after drug administration were below 
Table I. Glinical Data of Individual Subjects

\begin{tabular}{|c|c|c|c|c|c|c|c|c|}
\hline \multirow{2}{*}{\multicolumn{2}{|c|}{ Patient No. }} & \multirow{2}{*}{$\begin{array}{c}\text { Age } \\
\text { (year) }\end{array}$} & \multirow{2}{*}{ Sex } & \multirow{2}{*}{$\underset{(\mathrm{mmHg})}{\mathrm{MBP}}$} & \multirow{2}{*}{$\begin{array}{c}\text { Serum } \\
\text { Na } \\
(\mathrm{mEq} / \mathrm{L})\end{array}$} & \multirow{2}{*}{$\begin{array}{c}\text { Serum } \\
\mathrm{K} \\
(\mathrm{mEq} / \mathrm{L})\end{array}$} & \multicolumn{2}{|c|}{ PRA (ng/ml/h)* } \\
\hline & & & & & & & before & after \\
\hline \multirow[t]{18}{*}{$\mathrm{EH}$} & 1 & 29 & $f$ & 111 & 139 & 4.7 & 2.64 & 11.5 \\
\hline & 2 & 34 & $\mathrm{~m}$ & 141 & 142 & 3.5 & 2.28 & 8.51 \\
\hline & 3 & 36 & $\mathrm{~m}$ & 151 & 136 & 4.2 & 1.48 & 8.21 \\
\hline & 4 & 36 & $\mathrm{f}$ & 109 & 141 & 3.7 & 0.25 & 0.64 \\
\hline & 5 & 41 & $\mathrm{f}$ & 125 & 139 & 4.9 & 0.85 & 1.54 \\
\hline & 6 & 43 & $\mathrm{~m}$ & 126 & 137 & 4.1 & 0.52 & 1.32 \\
\hline & 7 & 43 & $f$ & 137 & 140 & 3.3 & 1.38 & 1.82 \\
\hline & 8 & 47 & $\mathrm{~m}$ & 110 & 141 & 3.7 & 2.73 & 5.72 \\
\hline & 9 & 50 & $\mathrm{f}$ & 141 & 144 & 3,8 & 2.68 & 6.82 \\
\hline & 10 & 51 & $f$ & 122 & 147 & 3.7 & 0.60 & 1.28 \\
\hline & 11 & 55 & $\mathrm{~m}$ & 107 & 145 & 4.8 & 2.03 & 3.37 \\
\hline & 12 & 56 & $\mathrm{~m}$ & 109 & 140 & 4.5 & 0.80 & 4.53 \\
\hline & 13 & 58 & $f$ & 126 & 141 & 3.7 & 0.64 & 2.63 \\
\hline & 14 & 59 & $\mathrm{~m}$ & 112 & 140 & 4.5 & 0.59 & 2.11 \\
\hline & 15 & 60 & $f$ & 113 & 138 & 3,7 & 0.61 & 2.07 \\
\hline & 16 & 61 & $\mathrm{~m}$ & 143 & 143 & 3.7 & 2.64 & 11.5 \\
\hline & 17 & 62 & $\mathrm{~m}$ & 105 & 140 & 3.9 & 0.15 & 0.50 \\
\hline & $\mathrm{m} \pm \mathrm{SD}$ & $48 \pm 10$ & & $123 \pm 15$ & $141 \pm 3$ & $4.0 \pm 0.5$ & $1.23 \pm 0.88$ & $3.93 \pm 3.12$ \\
\hline \multirow[t]{6}{*}{ RVH } & 18 & 30 & $f$ & 130 & 140 & 3.9 & 2.04 & 21.3 \\
\hline & 19 & 35 & $\mathrm{~m}$ & 115 & 140 & 4.4 & 1.23 & 5.20 \\
\hline & 20 & 44 & $\mathrm{~m}$ & 139 & 143 & 3.9 & 5.01 & 16.3 \\
\hline & 21 & 53 & $\mathrm{~m}$ & 126 & 142 & 4.5 & 1.86 & 7.40 \\
\hline & 22 & 57 & $f$ & 125 & 137 & 3.6 & 9.35 & 8.19 \\
\hline & $m \pm S D$ & $44 \pm 10$ & & $127 \pm 8$ & $140 \pm 2$ & $4.1 \pm 0.3$ & $3.90 \pm 3.02$ & $11.6 \pm 6.1$ \\
\hline \multirow[t]{3}{*}{$\mathrm{RH}$} & 23 & 33 & f & 150 & 143 & 4.8 & 1.63 & 2.54 \\
\hline & 24 & 43 & $\mathrm{~m}$ & 148 & 138 & 4.7 & 11.1 & 22.7 \\
\hline & $\mathrm{m} \pm \mathrm{SD}$ & $38 \pm 5$ & & $149 \pm 1$ & $141 \pm 3$ & $4.8 \pm 0.1$ & $6.37 \pm 4.74$ & $12.6 \pm 10.1$ \\
\hline \multirow[t]{8}{*}{ PA } & 25 & 27 & $\mathrm{~m}$ & 119 & 145 & 2.8 & 0.13 & 0.69 \\
\hline & 26 & 30 & $\mathrm{~m}$ & 119 & 139 & 3.6 & 0.10 & 0.10 \\
\hline & 27 & 35 & $f$ & 132 & 140 & 2.8 & 0.10 & 0.10 \\
\hline & 28 & 43 & $f$ & 121 & 143 & 2.2 & 0.19 & 0.20 \\
\hline & 29 & 46 & $\mathrm{~m}$ & 150 & 143 & 2.7 & 0.10 & 0.45 \\
\hline & 30 & 48 & $\mathrm{~m}$ & 133 & 141 & 3.0 & 0.10 & 0.52 \\
\hline & 31 & 56 & $f$ & 118 & 141 & 3.2 & 0.22 & 0.30 \\
\hline & $n \pm S D$ & $41 \pm 10$ & & $127 \pm 11$ & $142 \pm 2$ & $2.9 \pm 0.4 \uparrow$ & $0.13 \pm 0.05 t$ & $0.34 \pm 0.21 \dagger$ \\
\hline
\end{tabular}

* PRA before and after furosemide $1 \mathrm{mg} / \mathrm{Kg}$ i.v. and upright posture.

$\dagger$ Significant difference $(\mathrm{p}<0.01)$ compared with $\mathrm{EH}$ and $\mathrm{RVH}$.

$15 \mathrm{ng} / \mathrm{dl}$ in all patients with $\mathrm{EH}, \mathrm{RVH}, \mathrm{RH}$ and normal controls and greater than $15 \mathrm{ng} / \mathrm{dl}$ in 6 of 7 patients with PA. The PRA after captopril increased to greater than $1 \mathrm{ng} / \mathrm{ml} / \mathrm{h}$ in normal subjccts and all of the $\mathrm{RH}$ and $\mathrm{RVH}$ 

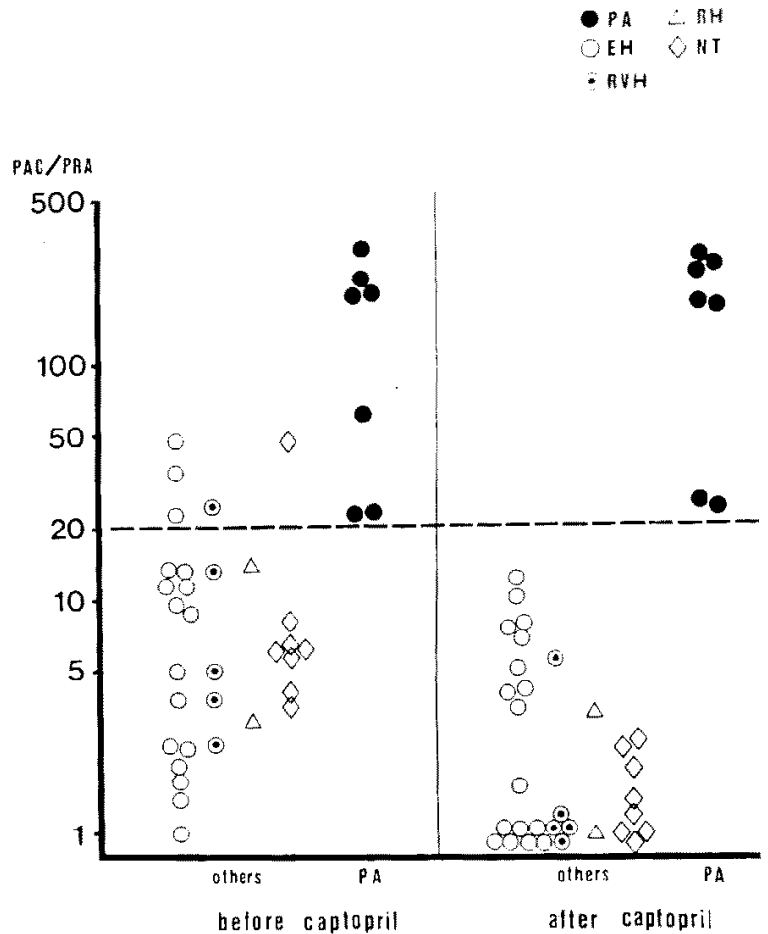

Fig. 1. The PAC to PRA ratios before and after $50 \mathrm{mg}$ captopril administration in patients with $\mathrm{PA}, \mathrm{EH}, \mathrm{RVH}, \mathrm{RH}$ and in normal subjects.

patients, whereas it was less than that in 7 of $17 \mathrm{EH}$ patients and 6 of 7 patients with PA. The aldosterone to renin ratios before and after captopril are shown in Table II and Fig. 1. The ratios before captopril were greater than 20 in all the PA and 3 of $17 \mathrm{EH}$ patients and one each of the $\mathrm{RH}$ and normal subjects. However, the ratios after captopril were never less than 20 in only the PA patients. This finding was unique to this group.

\section{Discussion}

The present study has assessed the usefulness of the captopril administration test in the screening of PA and confirmed its diagnostic accuracy for the disease. When we take into account the ratio of PAC to PRA at $90 \mathrm{~min}$ after captopril administration, it seems to be superior to any of the other methods currently used for the purpose.

Various simplified procedures have been developed to improve the diagnostic accuracy of mineralocorticoid-induced hypertension. Low serum potassium is a convenient compass in the screening of PA especially for outpatients; however, its diagnostic accuracy is unsatisfactory. It is widely ac- 
Table II. Results of Captopril Test

\begin{tabular}{|c|c|c|c|c|c|c|c|}
\hline & & \multicolumn{2}{|c|}{ PAC } & \multicolumn{2}{|c|}{ PRA } & \multicolumn{2}{|c|}{ PAC/PRA } \\
\hline & & $0 \mathrm{~min}$ & $90 \mathrm{~min}$ & $0 \mathrm{~min}$ & $90 \mathrm{~min}$ & $0 \mathrm{~min}$ & $90 \mathrm{~min}$ \\
\hline \multirow[t]{18}{*}{$\mathrm{EH}$} & 1 & 4.3 & 1.1 & 2.15 & 11.6 & 1.7 & 0.1 \\
\hline & 2 & 9.2 & 4.3 & 3.85 & 8.11 & 2.4 & 0.5 \\
\hline & 3 & 3.0 & 0.6 & 0.80 & 2.00 & 3.8 & 0.3 \\
\hline & 4 & 7.5 & 2.8 & 0.16 & 0.23 & 46.9 & 12.2 \\
\hline & 5 & 8.1 & 6.0 & 0.92 & 1.19 & 8.8 & 5.0 \\
\hline & 6 & 9.8 & 3.2 & 1.02 & 0.79 & 9.6 & 4.1 \\
\hline & 7 & 1,1 & 0.8 & 1.81 & 3.82 & 0.6 & 0.2 \\
\hline & 8 & 3.3 & 1.8 & 2.42 & 9.08 & 1.4 & 0.2 \\
\hline & 9 & 8.7 & 5.0 & 0.76 & 1.25 & 11.4 & 4.0 \\
\hline & 10 & 8.5 & 5.9 & 0.66 & 0.59 & 12.9 & 10.6 \\
\hline & 11 & 4.1 & 2.1 & 1.79 & 3.11 & 2.3 & 0.7 \\
\hline & $\mathrm{I} 2$ & 10.0 & 7.0 & 0.44 & 0.98 & 22.7 & 7.1 \\
\hline & 13 & 7.5 & 3.9 & 0.60 & 2.45 & 12.5 & 1.6 \\
\hline & 14 & 5.3 & 3.9 & 0.46 & 0.50 & 11.5 & 7.8 \\
\hline & 15 & 4.1 & 1.2 & 0.84 & 0.35 & 4.9 & 3.4 \\
\hline & 16 & 4.9 & 6.5 & 2.60 & 15.1 & 1.9 & 0.4 \\
\hline & 17 & 3.4 & 2.9 & 0.10 & 0.38 & 34.0 & 7.6 \\
\hline & $\mathrm{m} \pm \mathrm{SD}$ & $6.1 \pm 2.7$ & $3.5 \pm 2.0$ & $1.28 \pm 1.01$ & $2.20 \pm 2.53$ & $11.1 \pm 12.3$ & $3.8 \pm 3.8$ \\
\hline \multirow[t]{6}{*}{$\mathrm{RVH}$} & 18 & 8.6 & 5.7 & 1.70 & 25.3 & 5.1 & 0.2 \\
\hline & 19 & 13.6 & 7.8 & 1.03 & 1.43 & 13.2 & 5.5 \\
\hline & 20 & 16.4 & 12.4 & 4.26 & 61.4 & 3.8 & 0.2 \\
\hline & 21 & 6.3 & 3.3 & 2.67 & 40.1 & 2.4 & 0.1 \\
\hline & 22 & 20.2 & 11.7 & 0.82 & 9.40 & 24.6 & 1.2 \\
\hline & $\mathrm{m} \pm \mathrm{SD}$ & $13.0 \pm 5.1$ & $8.2 \pm 3.5$ & $2.09 \pm 1.26$ & $27.5 \pm 21.5$ & $9.8 \pm 8.3$ & $1.4 \pm 2.1$ \\
\hline \multirow[t]{3}{*}{$\mathrm{RH}$} & 23 & 19.9 & 7.9 & 1.50 & 2.44 & 13.3 & 3.2 \\
\hline & 24 & 22.5 & 14.5 & 7.73 & 30.8 & 2.9 & 0.5 \\
\hline & $m \pm S D$ & $21.2 \pm 1.3$ & $11.2 \pm 3.3$ & $4.62 \pm 3.12$ & $16.6 \pm 14.8$ & $8.1 \pm 5.2$ & $1.9 \pm 1.4$ \\
\hline \multirow[t]{8}{*}{ PA } & 25 & 25.2 & 32.9 & 1.77 & 1.32 & 21,5 & 24.9 \\
\hline & 26 & 18.6 & 26.8 & 0.10 & 0.10 & 186 & 268 \\
\hline & 27 & 22.4 & 23.5 & 0.10 & 0.10 & 224 & 235 \\
\hline & 28 & 20.2 & 26.3 & 0.93 & 0.15 & 21.9 & 175 \\
\hline & 29 & 25.0 & 11.3 & 0.41 & 0.46 & 60.9 & 24.6 \\
\hline & 30 & 19.3 & 16.8 & 0.10 & 0.10 & 193 & 168 \\
\hline & 31 & 45.6 & 37.9 & 0.15 & 0.15 & 304 & 253 \\
\hline & $\mathrm{m} \pm \mathrm{SD}$ & $25.2 \pm 8.7^{*}$ & $25.1 \pm 8.4 *$ & $0.42 \pm 0.41 \#+$ & $0.34 \pm 0.42 \# \dagger$ & $144 \pm 102^{*}$ & $164 \pm 94.6^{*}$ \\
\hline \multicolumn{2}{|c|}{ NC $(n=8)$} & & & & & & \\
\hline & $n \pm S D$ & $7.0 \pm 4.3$ & $4.1 \pm 3.0$ & $1.03 \pm 0.73$ & $6.59 \pm 9.02$ & $10.8 \pm 13.5$ & $1.3 \pm 0.8$ \\
\hline
\end{tabular}

* Significant difference $(p<0.01)$ compared with EH, RVH and NC.

\# Significant difference $(p<0.01)$ compared with RVH.

+ Significant difference $(\mathrm{p}<0.05)$ compared with $\mathrm{EH}$ and $\mathrm{NC}$. 
cepted that a more dependable marker to detect $\mathrm{PA}^{11}$ is the suppression of PRA after i.v. furosemide followed by 1 or 2 hours of upright posture, but we failed to distinguish the disease completely from so-called low renin $\mathrm{EH}$. Moreover, some of our female patients were unable to maintain upright posture for 2 hours after furosemide administration. Therefore, a more adequate diagnostic test for PA is needed.

Recently, Lyon et al $^{8)}$ have reported on the usefulness of captopril as an alternative tool to diagnose PA. It has been noticed that the drug has no effect on aldosterone production in patients with PA because of the autonomous production of the steroid. We previously reported that the captopril test was a simple and safe test to evaluate the role of the renin angiotensin system in hypertensive patients. ${ }^{10)}$ Therefore, we concentrated on the usefulness of the drug for the diagnosis of PA. As stated by Lyon et al, 6 of our 7 patients with PA also showed a PAC of greater than $15 \mathrm{ng} / \mathrm{dl}$ at $90 \mathrm{~min}$ after the administration of captopril, while patients with other forms of hypertension did not. However, we still could not diagnose as PA one patient with PA, proven to have an aldosteronoma by operation, using only this criterion. On the other hand, captopril increases PRA by decreasing the negative feedback of angiotensin II in patients with $\mathrm{EH}$, but has little effect on PRA in patients with PA. However, in the present study, 7 of 17 patients with EH failed to increase their PRA above $1 \mathrm{ng} / \mathrm{ml} / \mathrm{h}$ after the administration of captopril, and thus might be classified in the low renin group of EH. Therefore, the response of PRA itself to the drug cannot be a reasonable criterion. Lyon et $\mathrm{al}^{81}$ also proposed the use of an aldosterone to renin ratio of 50 to separate $\mathrm{PA}$ from other forms of hypertension. When we used a ratio of 50, 2 of our PA patients had to be grouped in EH. Therefore, it seems a reasonable criterion to use a ratio of 20 in our study because all our patients with PA showed ratios greater than that and none of the patients with other forms of hypertension including $\mathrm{EH}, \mathrm{RVH}$ and $\mathrm{RH}$ had ratios below 20. Further expanded studies will be needed to decide on the proper ratio to be set as the borderline to separate PA patients from others.

It is widely accepted that the lack of suppression of PAC by a saline infusion might be a most reliable diagnostic criterion for PA. However, the test is at times not easily performed in patients with severe hypertension because of the acute loading of 2 liters of saline. In contrast, the captopril test has no marked side effects and can be performed within 2 hours. Therefore, the captopril test might be a convenient, less harmful and more accurate test for the diagnosis of PA. In addition, the effect of sodium intake on the $P A C$ to $P R A$ ratio after captopril is under investigation in an attempt to apply the test to outpatients without the necessity of employing dietary sodium 
manipulation.

\section{References}

1. Conn JW: Primary aldosteronism: A new clinical syndrome. J Clin Lab Med 45: 6, 1955

2. Conn JW, Rovner DR, Cohen EL, Bookstein JJ, Cerney JC, Lucas CP: Preoperative diagnosis of primary aldosteronism. Arch Intern Med 123: 113, 1969

3. Baglin A, Weiss X, Safter M, Milliez P: Hyperaldosteronism primarie avec Hypertension Maligne. Le Nouvelle Presse Medicale 2: 5, 1973

4. Iwaoka $T$, Umeda $T$, Sato $T$, Katsuragi $S$, Takeuchi $T$ : High plasma renin activity in primary aldosteronism with malignant hypertension. A case report. Jpn Heart J 21: 423, 1980

5. Collins RD, Weinberger MH, Dowdy AJ, Nokes GW, Gonzales CM, Luetscher JA: Abnormally sustained aldosterone secretion during salt loading in patients with various forms of benign hypertension: relation to plasma renin activity. J Clin Invest 49: 1415, 1970

6. Salton DE Jr, Schambelan M, Biglieri EG: Stimulation and suppression of aldosterone secretion in patients with aldosterone-producing adenoma. J Clin Endocrinol Metab 29: 239, 1969

7. Kem DC, Weinberger MH, Mayes DM, Nugent CA: Saline suppression of plasma aldosterone in hypertension. Arch Intern Med 128: 380, 1971

8. Lyon DF, Kem DC, Brown RD, Hanson CS, Carollo ML: Single dose captopril as a diagnostic test for primary aldosteronism. J Clin Endocrinol Metab 57: 892, 1983

9. Luderer DF, Demers LM, Hrrison TS, Hayes AH Jr: Converting enzyme inhibition with captopril in patients with hyperaldosteronism. Clin Pharmacol Ther 31: 305, 1982

10. Iwaoka $\mathrm{T}$ : Clinical evaluation of renin angiotensin system in hypertensive patients with oral angiotensin converting enzyme inhibitor. Kumamoto Med J 36: 79, 1983

11. Weinberger MH, Grim CE, Hollifeld JW, Kem DC, Ganguly A, Kramer NJ, Yune HY, Wellman H, Donohue JP: Primary aldosteronism: diagnosis, localization, and treatment. Ann Int Med 90: 386, 1979 